\title{
Kindlin-1 contributes to EGF-induced re-epithelialization in skin wound healing
}

\author{
CONGCONG SHEN ${ }^{1,2}$, LINLIN SUN $^{3}$, NINGWEN ZHU ${ }^{4}$ and FAZHI QI ${ }^{1}$ \\ ${ }^{1}$ Department of Plastic Surgery, Zhongshan Hospital, Fudan University, Shanghai 200032; \\ ${ }^{2}$ Department of Dermatology and Venereology, Affiliated Hospital of Nantong University, Nantong 226001; \\ ${ }^{3}$ Department of Biochemistry and Molecular Biology, Basic Medical College of Fudan University, Shanghai 200032; \\ ${ }^{4}$ Department of Dermatology, Huashan Hospital, Fudan University, Shanghai 200040, P.R. China
}

Received March 14, 2016; Accepted February 21, 2017

DOI: 10.3892/ijmm.2017.2911

\begin{abstract}
The commercial use of epidermal growth factor (EGF) is extensive and has been shown to be effective for skin wound healing in clinical practice. There is evidence to indicate that the topical administration of EGF significantly accelerates re-epithelialization by promoting keratinocyte mitogenesis and migration following acute injury; however, the mechanisms involved remain to be elucidated. Thus, in this study, we focused on Kindlin-1, a four-point-one, ezrin, radixin, moesin (FERM)-domain-containing adaptor protein, and report its contribution to EGF-induced re-epithelialization in skin wound healing. In tissue samples, the expression of Kindlin-1 was induced upon EGF treatment compared to that in the natural healing group. In immortalized human keratinocytes (HaCaT cells), we further proved that Kindlin-1 was necessary for mediating EGF-induced activation signals, including integrin $\beta 1$ activation, focal adhesion kinase (FAK) phosphorylation and actin re-organization, which finally led to enhanced cell proliferation and migration. These results indicate that Kindlin-1 is essential in EGF-induced re-epithelialization in skin wound healing and provide additional rationale for the clinical application of EGF in the treatment of acute wounds.
\end{abstract}

\section{Introduction}

Skin wound healing begins immediately following an injury and consists of several overlapping stages: hemostasis,

Correspondence to: Professor Fazhi Qi, Department of Plastic Surgery, Zhongshan Hospital, Fudan University, No. 180 Feng Lin Road, Shanghai 200032, P.R. China

E-mail: qi.fazhi@zs-hospital.sh.cn

Professor Ningwen Zhu, Department of Dermatology, Huashan Hospital, Fudan University, No. 12 Middle Wu Lu Mu Qi Road, Shanghai 200040, P.R. China

E-mail:drnwzhu@126.com

Key words: Skin wound healing, Kindlin-1, EGF, re-epithelialization, $\mathrm{HaCaTs}$ inflammation, proliferation and remodeling (1). These phases proceed with well-organized interaction among various types of cells, including platelets, keratinocytes, fibroblasts, endothelial cells and macrophages.

Keratinocytes, the major cellular component of the epidermis, are critical to wound re-epithelialization. Under normal conditions, several layers of keratinocytes form the integumentary system, providing a physical barrier between the environment and the organism, thereby protecting the body from external agents and pathogens (2). Once injured, keratinocytes undergo migration, proliferation and differentiation in order to maintain the integrity of the skin barrier.

Stimuli that prompt keratinocyte activation include growth factors, cytokines and chemokines (3-5). Epidermal growth factor (EGF) may be one of the most well-characterized growth factors in skin wound healing. In acute wounds, EGF is mainly secreted by platelets, macrophages and fibroblasts and is upregulated within a short period of time following injury $(6,7)$. The release of EGF stimulates epithelial cell migration and proliferation, thus contributing to re-epithelialization (8).

A great deal of research efforts have focused on understanding the mechanisms of EGF responses in keratinocytes. Increased integrin expression can be detected in EGF-stimulated corneal keratinocytes, and has been proven to be responsible for the downstream events triggered by EGF (9). As regards re-epithelialization, integrins serve as cell attachment receptors and mediators of cellular signaling. Compared to the other subunits, the $\beta 1$ family integrins are relatively well established: the increased expression of $\alpha 2 \beta 1, \alpha 3 \beta 1, \alpha 9 \beta 1, \alpha 5 \beta 1$ and $\alpha \mathrm{V} \beta 1$ can be detected in the epidermis after wounding $(10,11)$; the loss of $\beta 1$ integrins in keratinocytes results in defective migration (12); the conditional deletion of the $\beta 1$ subunit in the mouse epidermis has been shown to prevent re-epithelialization and inhibit the closure of excisional wounds (13). All these clues point to the vital role of $\beta 1$ integrins in wound healing.

To fully understand integrin bidirectional signaling, numerous researchers have focused on integrin binding proteins, which are critical in bridging integrin to various signaling pathways. For example, talin and intergrin-linked kinases (ILK) (14). Recent studies reported that Kindlins, a protein family structurally related to talin, also act as adaptor molecules by i) cooperating with talin to activate integrin (15), 
and ii) linking integrin with the cytoskeleton, scaffolding and signaling proteins by interacting with ILK, and recruiting proteins to focal adhesions $(16,17)$. Given such findings, we attempted to explore the potential role of Kindlin-1 in EGF-induced wound healing.

Kindlins are evolutionary conserved, FERM-domaincontaining adaptor proteins which play a vital role in integrin activation $(18,19)$. All three members of the Kindlin family can directly bind to the membrane distal NPxY motifs within cytoplasmic integrin $\beta$ tails, recruit cytoskeletal proteins and therefore activate intracellular cell signal transduction, as well as integrin binding to extracellular ligands (20). Among the Kindlins, Kindlin-1 is widely expressed in murine and human tissues, including the skin, heart, lungs, liver, kidneys, colon, prostate, ovaries and pancreas, and is predominantly distributed in epithelia $(21,22)$. Mutations in the Kindlin-1 gene have been shown to cause Kindler syndrome, a rare human disease characterized by a variety of skin abnormalities, including skin blisters, photosensitivity, mucosal erosion and skin cancer (23), indicating that Kindlin-1 is critical in maintaining the normal function of the skin. However, the functions of Kindlin-1 in skin wound healing are not yet fully understood, although it has been previously demonstrated that a deficiency in Kindlin-1 results in reduced cell adhesion and increased apoptosis in keratinocytes (24).

In the present study, we first demonstrate that Kindlin-1 is involved in the natural skin wound healing process and in particular, it contributes to EGF-induced re-epithelialization in skin wound healing. The use of shRNA targeting Kindlin-1 efficiently suppressed EGF-induced HaCaT activation, including migration and proliferation by suppressing integrin $\beta 1$ activation, focal adhesion kinase (FAK) phosphorylation and actin re-organization. Our data not only provide new mechanistic insight into the regulation of re-epithelialization in skin wound healing, but also lead to an improved understanding of the molecular basis underlying the application of EGF in the treatment of wounds.

\section{Materials and methods}

Ethics statement. Animal experiments were performed in strict accordance with the recommendations in the Guide for the Care and Use of Laboratory Animals of the National Institutes of Health, which conforms to the provisions of the Declaration of Helsinki. The protocol was approved by the Ethics Committee of Fudan University, Shanghai, China. All surgerical procedures were performed under sodium pentobarbital anesthesia, and all efforts were made to minimize animal suffering.

Wound model. Balb/c mice (Slac Laboratory Animal Co., Ltd., Shanghai, China) were deeply anesthetized before shaving the dorsal hair and cleaning the exposed skin with $70 \%$ ethanol. Subsequently, $5 \mathrm{~mm}$ full thickness punch wounds were created through the skin and the panniculus carnosus on the dorsal surface (one wound each on the left and right side) of each mouse. For further experiments, including immunohistochemical anlaysis, real-time PCR and western blot analysis, the healed tissues were removed en bloc with a $7 \mathrm{~mm}$ punch to include a margin of unwounded skin at the indicated time intervals; the unwounded back skin tissues removed at day 0 were used as controls [in the following results, the controls are presented as 'normal', EGF(-) day 0 or $\mathrm{EGF}(+)$ day 0$]$.

Experimental groups and treatment. A total of $60 \mathrm{Balb} / \mathrm{c}$ mice (8-9 weeks old) were randomly divided into 10 groups as follows: i) EGF(-) (wound model, but no EGF treatment) 1 day group; ii) $\mathrm{EGF}(-) 3$ day group; iii) $\mathrm{EGF}(-) 7$ day group; iv) $\mathrm{EGF}(-) 10$ day group; v) $\mathrm{EGF}(-) 14$ day group; vi) $\mathrm{EGF}(+)$ (wound model with EGF treatment) 1 day group; vii) $\mathrm{EGF}(+)$ 3 day group; viii) $\mathrm{EGF}(+) 7$ day group; ix) $\mathrm{EGF}(+) 10$ day group; and $\mathrm{x}) \mathrm{EGF}(+) 14$ day group. In the $\mathrm{EGF}(+)$ group, the wounds were treated with EGF (recombinant human epidermal growth factor derivative for external use, liquid (I), 2,000 IU/ml, S20010038; Shenzhen Watsin Genetech Co., Ltd. Shenzhen, China) once a day (spray once on each wound). In each group, 6 animals were included. At the end of the experiment, mice were sacrificed by cervical dislocation under anesthesia.

Immunohistochemistry and immunofluorescence staining. For immunohistochemical staining, fresh skin tissues were embedded by optimal cutting temperature (OCT) compound. Frozen sections of skin $(10-\mu \mathrm{m}$-thick) were stained with rabbit polyclonal Kindlin-1 antibody (22215-1-AP; Proteintech Group Inc., Chicago, IL, USA) at a dilution of 1:100 overnight $\left(4^{\circ} \mathrm{C}\right)$ and then incubated with Dako REAL ${ }^{\mathrm{TM}}$ EnVision $^{\mathrm{TM}} / \mathrm{HRP}$, Rabbit/Mouse (ENV) reagent (K5007; DAKO, Glostrup, Denmark). For tissue immunofluorescence staining $(25,26)$, the frozen tissues were stained with F4/80 (a marker of macrophages), Keratin 6 (K6, a marker of keratinocytes), FSP1 (a marker of fibroblasts) and Kindlin-1 antibodies. For cell immunofluorescence staining, the cells were first fixed with $4 \%$ paraformaldehyde for $10 \mathrm{~min}$ at room temperature, rinsed with PBS and incubated in blocking solution for $60 \mathrm{~min}$ at room temperature. For Kindlin-1, activated integrin $\beta 1$ [(integrin $\beta 1$ (ac)] and phospho-FAK (p-FAK) labeling, the cells were incubated with the primary antibody for $2 \mathrm{~h}$ at room temperature, rinsed with PBS and incubated with the relevant secondary antibody for $1 \mathrm{~h}$ at room temperature; For actin staining, the cells were incubated with PhalloidiniFluor 594 Conjugate (cat. no. 23122; 1:1,000; AAT Bioquest, Sunnyvale, CA, USA) followed by DAPI staining (Sigma, St. Louis, MO, USA). The following antibodies were used: rabbit polyclonal Kindlin-1 antibody (cat. no. 22215-1-AP; 1:50; Proteintech Group Inc.), mouse monoclonal activated integrin $\beta 1$ antibody (cat. no. MAB2079Z; 1:300, Millipore, Bedford, MA, USA), mouse monoclonal Kindlin-1 antibody (cat. no. SAB4200465; 1:250; Sigma), rabbit monoclonal phospho-FAK (Tyr397) antibody (cat. no. EP2160Y; 1:400; Abcam, Cambridge, UK), DyLight 405 affinipure goat antirabbit IgG (H+L) (cat. no. A23120; 1:800; Abbkine, Los Angeles, CA, USA), DyLight 405 affinipure goat anti-mouse IgG (H+L) (cat. no. A23110; 1:800; Abbkine), Alexa Fluor 594 affinipure goat anti-mouse IgG (H+L) (cat. no. 115-585-003; 1:800; Jackson ImmunoResearch, West Grove, PA, USA), Alexa Fluor 594 affinipure goat anti-rabbit IgG $(\mathrm{H}+\mathrm{L})$ (cat. no. 111-585-003; 1:800; Jackson ImmunoResearch). Images were captured using a Nikon Eclipse 660 microscope (Nikon, Tokyo, Japan) or a confocal laser scanning microscope (Leica Microsystems, Wetzlar, Germany). A total of 6 samples from each group was selected. For each sample, at least 4 fields were captured. 
Cell culture and RNA interference-induced knockdown of Kindlin-1. The immortalized keratinocyte cell line, HaCaT, (KCB 200442YJ, Kunming Cell Bank of Chinese Academy of Science, Kunming, China), were kept in Dulbecco's modified Eagle's medium (DMEM), containing $10 \%$ fetal bovine serum and $1 \%$ penicillin/streptomycin. To inhibit the expression of Kindlin-1 in the HaCaT cells, shRNA targeting Kindlin-1 [EGFP-Kindlin-1 shRNA (hu)] lentiviral particles (Genechem, Shanghai, China), a pool of viral particles containing 3 targetspecific constructs that encode 19 nt shRNA designed to knock down Kindlin-1 expression in the HaCaT cells, were transduced into the cells according to the manufacturer's instructions. Control lentiviral particles (Genechem) containing a scrambled shRNA sequence, were used as a negative control. The knockdown efficiency was confirmed by western blot analysis.

Real-time PCR. Real-time PCR was performed using the SYBR Primer Ex Taq ${ }^{\mathrm{TM}}$ II kit (Takara, Dalian, China). Data were obtained using the StepOne plus system (Applied Biosystems, Foster City, CA, USA). The relative change in Kindlin-1 mRNA expression was determined by the fold change. The sequences of the primers used were as follows: Mouse Kindlin-1 sense primer $\left(5^{\prime} \rightarrow 3^{\prime}\right)$, GGAGAGCAGCA GACAGAGAT; antisense primer $\left(5^{\prime} \rightarrow 3^{\prime}\right)$, TGCTGAGGGGTG AAGAGAAG. Mouse GAPDH sense primer $\left(5^{\prime} \rightarrow 3^{\prime}\right)$, GAGCG AGACCCCACTAACAT; antisense primer $\left(5^{\prime} \rightarrow 3^{\prime}\right)$ : TCTCCAT GGTGGTGAAGACA.

Western blot analysis. Western blot analysis was carried out as previously described (25). Briefly, tissues and cell lysates were collected, and the protein concentrations were determined using a BCA $^{\mathrm{TM}}$ Protein Assay kit (Pierce, Chemical Co., Rockford, IL, USA). Proteins were separated by $10 \%$ SDS-PAGE and electro-transferred onto PVDF membranes (Millipore). The membranes were first incubated with the indicated primary antibodies overnight $\left(4^{\circ} \mathrm{C}\right)$, followed by HRP-conjugated secondary antibodies for $2 \mathrm{~h}$ (room temperature). Blots were visualized using an enhanced chemiluminescence detection kit (Tiangen Biotech Co., Ltd. Beijing, China). The following antibodies were used: mouse monoclonal Kindlin-1 antibody (cat. no. SAB4200465; 1:1,000, Sigma), rabbit monoclonal integrin $\beta 1$ antibody (cat. no. NB110-57123; 1:1,000, Novus Biologicals, Littleton, CO, USA), mouse monoclonal activated integrin $\beta 1$ antibody (cat. no. MAB2079Z; 1:1,000, Millipore), rabbit polyclonal FAK antibody (cat. no. 3285; 1:1,000, Cell Signaling Technology, Inc., Danvers, MA, USA), rabbit monoclonal Phospho-FAK (Tyr397) antibody (cat. no. 8556; 1:1,000, Cell Signaling Technology, Inc.), rabbit monoclonal GAPDH antibody (cat. no. 3683, 1:1,000; Cell Signaling Technology, Inc.). All experiments were repeated at least 4 times.

Induction of FAK activation in HaCaTs. Fibronectin (FN, PHE0023; Gibco, Frederick, MD, USA), was used to induce cell adhesion. Briefly, dishes were coated with FN $(10 \mu \mathrm{g} / \mathrm{ml}$, $37^{\circ} \mathrm{C}$ ) overnight. Detached serum-starved control HaCaT cells and Kindlin-1 shRNA-transfected HaCaT cells were stimulated with or without EGF $(10 \mathrm{ng} / \mathrm{ml})$ for $15 \mathrm{~min}$ and were then subjected to FN-coated dishes. Cells were harvested at $30 \mathrm{~min}$, $1 \mathrm{~h}$ and $3 \mathrm{~h}$, respectively, and FAK phosphorylation was detected by western blot analysis.
Migration assay. Migration assay was performed using Transwell cell culture systems (3422; Corning, NY, USA), as previously described (26). Briefly, the HaCaT cells were added into the upper chamber. In order to verify the role of FAK in HaCaT cell migration, normal cells were first treated with or without FAK inhibitor, PF573228 (S2013; Selleck, Houston, TX, USA) (1 $\mu \mathrm{M}, 30 \mathrm{~min})$ and then treated with or without recombinant human EGF (236-EG; R\&D Systems, Minneapolis, MN,USA) (10 ng/ml) for $24 \mathrm{~h}$. In order to investigate the role of Kindlin-1 in HaCaT cell migration, normal, Kindlin-1 shRNA and control shRNA cells were treated with or without recombinant human EGF $(10 \mathrm{ng} / \mathrm{ml})$ for $24 \mathrm{~h}$. The infiltrating cells were stained with crystal violet (Beyotime, Shanghai, China), and cell numbers were counted from 5 wells. All experiments were repeated 3 times.

Cell proliferation assay. Cell proliferation was determined using the Cell Counting Kit-8 (CCK-8; Dojindo, Kunamoto, Japan) following the instruction manual. In brief, the cells were treated with or without EGF $(10 \mathrm{ng} / \mathrm{ml})$ for $24 \mathrm{~h}$ and then incubated with CCK-8 solution for $1.5 \mathrm{~h}$. The absorbance was determined at $450 \mathrm{~nm}$ using a Universal Microplate Reader (Bio-Tek Instruments Inc., Winooski, VT, USA). All assays were performed in triplicate, and the experiment was repeated 5 times.

Statistical analysis. The results are presented as the means \pm SEM. Statistical analysis was performed using One-way ANOVA. Statistical significance was determined at the level of $\mathrm{P}<0.05$.

\section{Results}

Dynamic expression of Kindlin-1 in EGF-induced skin wound healing in mice. In our initial set of experiments, we examined Kindlin-1 expression in skin tissues. Animals that underwent incisions were randomly divided into 2 main groups (with or without EGF treatment) and raised for different periods of time (Fig. 1A1). As shown in Fig. 1A2, the topical application of EGF improved the healing rate $(72.73 \%$ vs. $90.54 \%$ on the 14th day). Kindlin-1 mRNA expression was assessed by real-time PCR. As shown in Fig. 1B, the mRNA expression of Kindlin-1 reached the highest level at 1 day post-injury. The administration of EGF resulted in the more rapid and prolonged increase of Kindlin-1 mRNA expression. Similar alterations were observed by western blot analysis (Fig. $1 \mathrm{C} 1$ and $\mathrm{C} 2$ ). The dynamic expression of Kindlin-1 suggested that it is involved in the process of skin wound healing and is very likely to contribute to EGF signaling.

Distribution of Kindlin-1 in skin wounds. The distribution of Kindlin-1 was detected by immunostaining. As shown in Fig. 2A, in normal skin, Kindlin-1 was mainly located in the epidermis with low intensity. During the natural healing process [EGF(-) group, Fig. 2B-D], strong Kindlin-1 staining was found 3 days after wounding, mainly distributed in the epidermis and sporadically in the new dermal fibroblasts (Fig. 2B). On the 7th day, moderate Kindlin-1-positive staining was observed in the regenerated epidermis, which decreased with the distance from the wound center (Fig. 2C). On the 14th day, only weak Kindlin-1 staining was observed in 

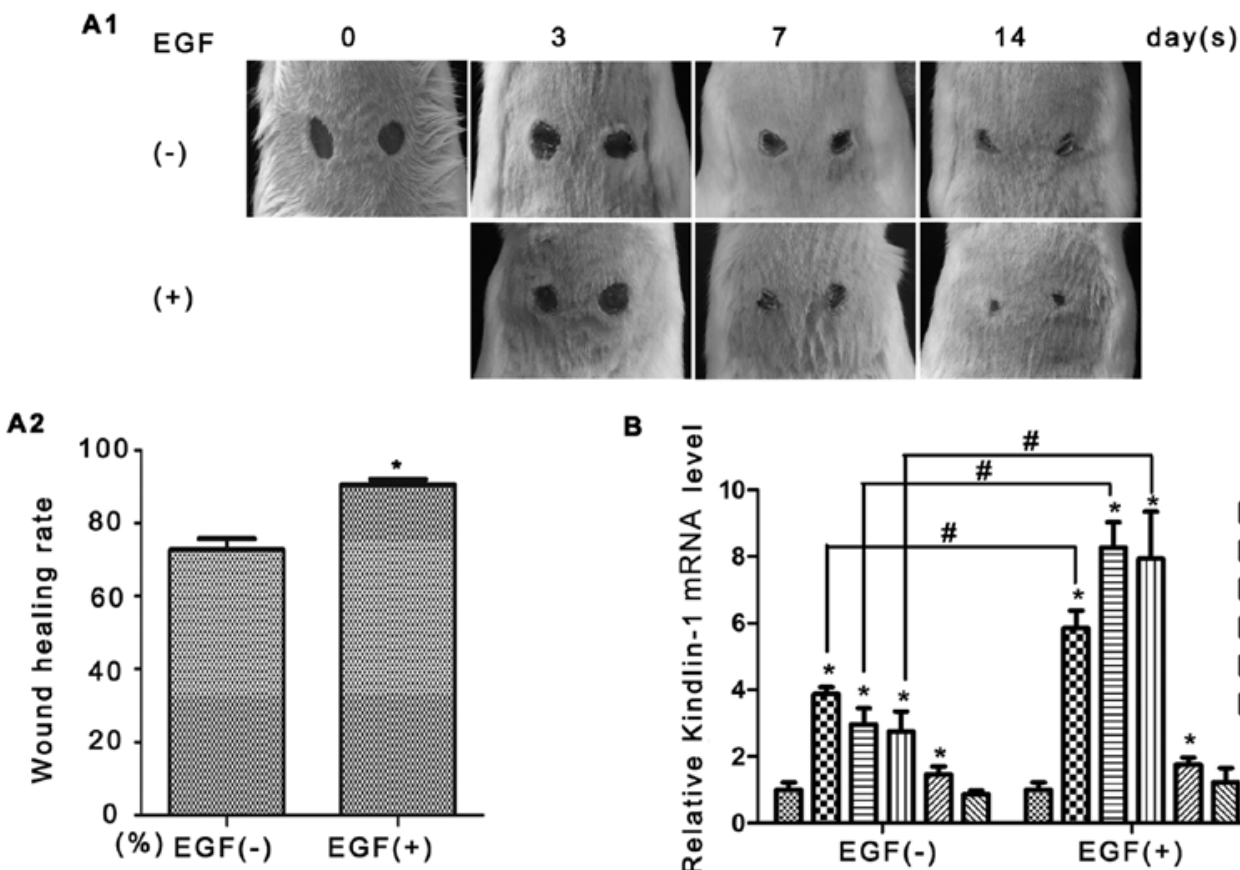

B
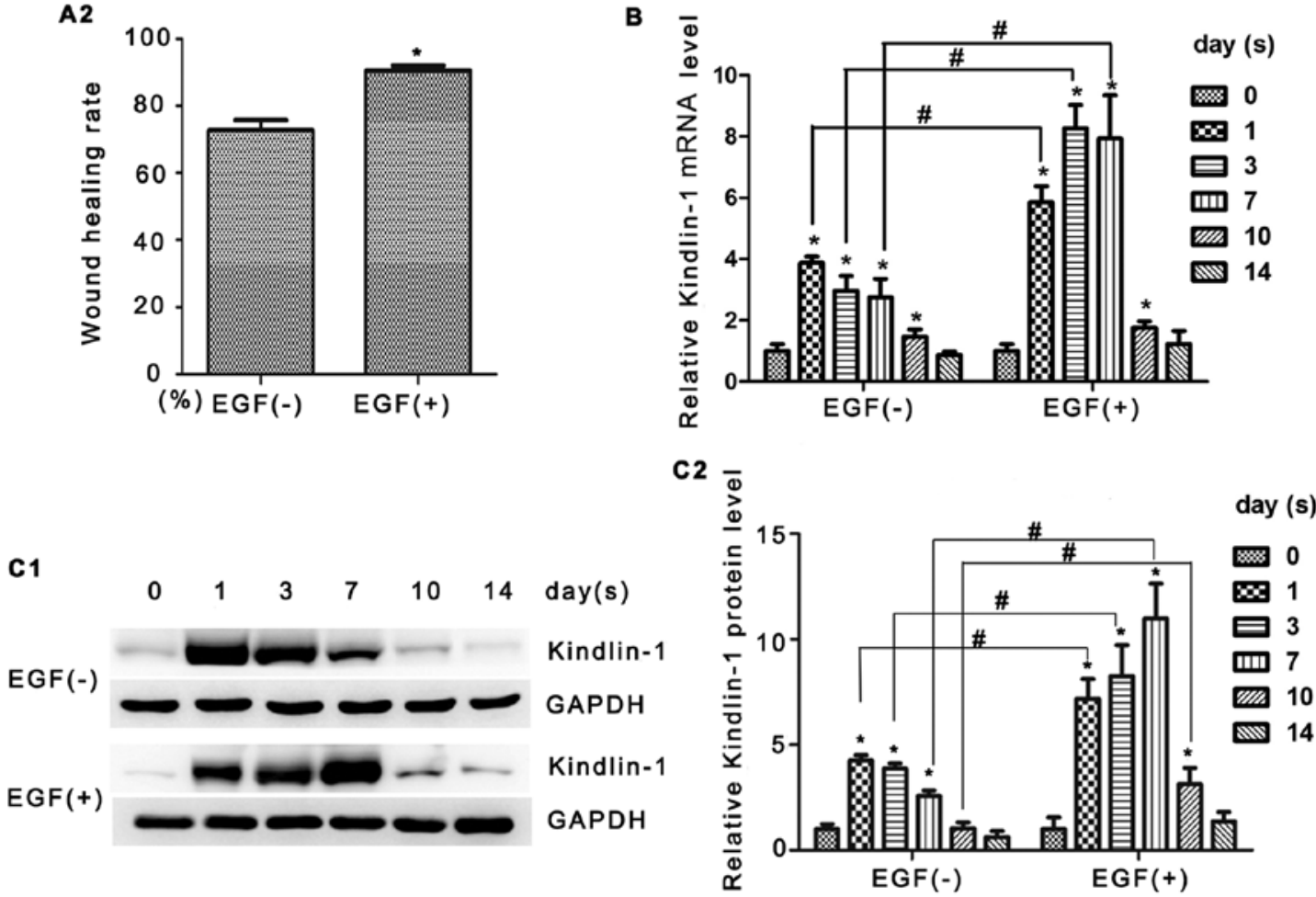

Figure 1. Dynamic expression of Kindlin-1 in skin wound healing in mice. Assessment of Kindlin-1 in skin wound healing in mice with or without EGF treatment. (A1)Construction of wound healing model in mice. (A2) Healing rate of EGF(-) and EGF(+) group at the 14th day. "P<0.05. (B1) Kindlin-1 expression was detected by real-time PCR. (C1) Kindlin-1 expression was detected by western blot analysis and with GAPDH as an internal control. (C2) Kindlin-1 expression was quantified and presented by the fold changes compared with the relative control [value of EGF(-) 0 days or EGF(+) 0 days]. " $\mathrm{P}<0.05$, significant difference compared to the normal group [EGF(-) 0 days, $\mathrm{EGF}(+) 0$ days]. ${ }^{~} \mathrm{P}<0.05$.

A

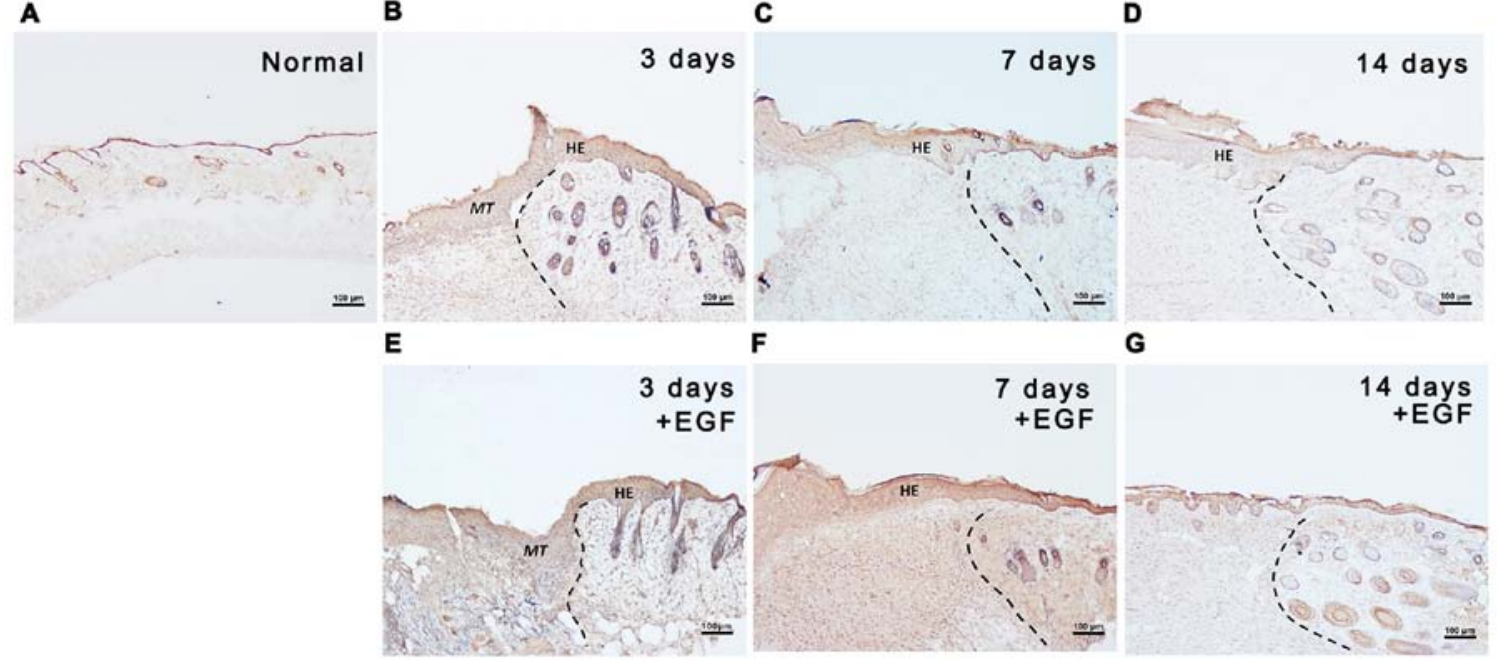

Figure 2. Distribution of Kindlin-1 in mouse skin tissues. Expression pattern of Kindlin-1 in mouse tissue slices was observed at the indicated time intervals after operation. (A) Normal; (B-D) EGF(-) 3 days, 7 days and 14 days, respectively; (E-G) EGF(+), 3 days, 7 days and 14 days, respectively. MT, migratory tongue; HE, hyperproliferative epithelium. The dotted line indicates the wound edge. Scale bar, $100 \mu \mathrm{m}$. 


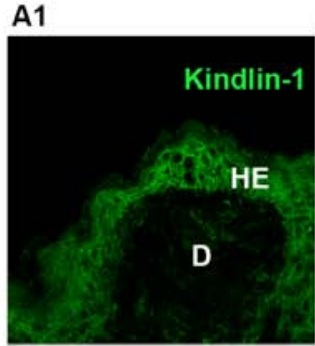

B1

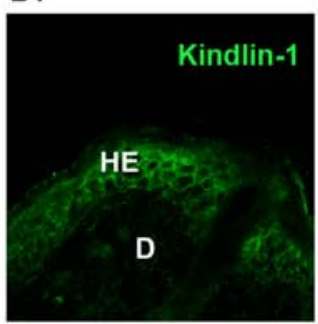

C1



A2

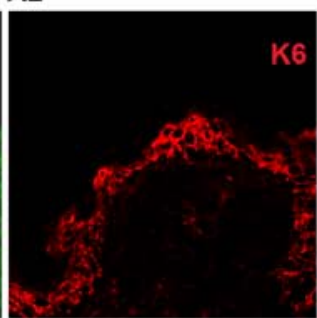

B2



C2

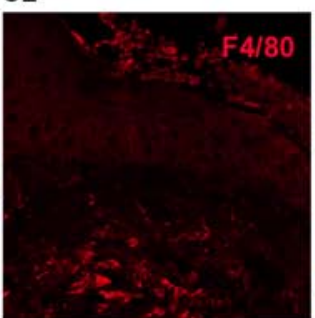

A3

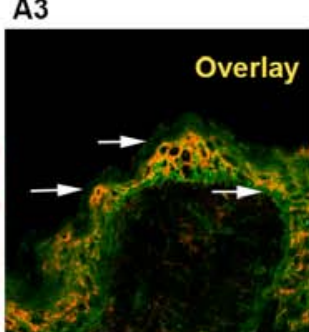

B3

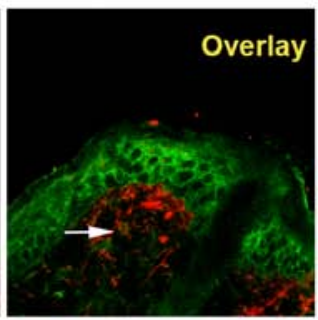

c3
A4

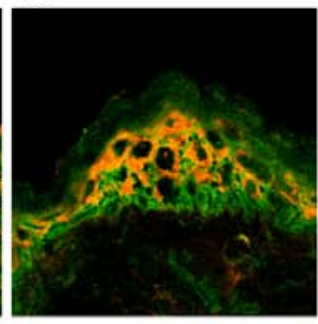

B4

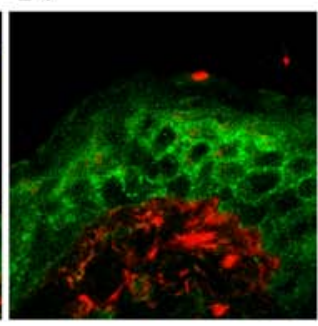

C4
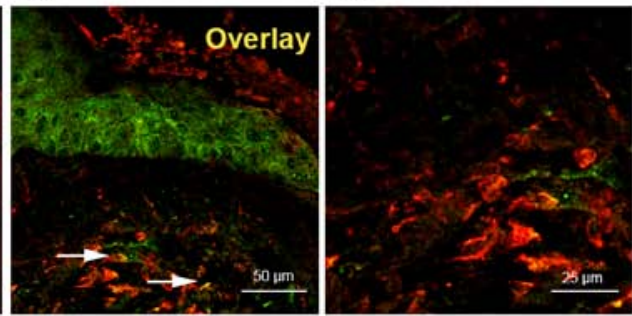

Figure 3. Cell location of Kindlin-1. Cell location of Kindlin-1 was observed in the EGF(+) 3 day group. Kindlin-1 (green) was double stained with K6 (A2-A3, red) FSP1 (B2-B3, red) and F4/80 (C2-C3, red); arrows indicate co-localization; scale bar, $50 \mu \mathrm{m}$. A4, B4 and C4 show an enlarged image; scale bar, $25 \mu \mathrm{m}$.

the wound epidermis (Fig. 2D). A more intense kindlin-1-positive signal was observed in the EGF(+) group (Fig. 2E-G); the most intense staining was found in the epidermal cells postinjury. Double labeling immunofluorescence (Fig. 3) further indicated that most of Kindlin-1 was located in the keratinocytes (Fig. 3A4), and to a lesser extent in fibroblasts (Fig. 3B4) and macrophages (Fig. 3C4). The specific accumulation of Kindlin-1 in keratinocytes encouraged us to further investigate the possible role of Kindlin-1 in re-epithelialization.

Expression of Kindlin-1 in EGF induces HaCaT cell activation in vivo. As mentioned above, keratinocytes are major cell components in re-epithelialization, EGF accelerates keratinocyte migration, induces rapid proliferation and exerts its effects in a paracrine manner $(7,8)$. Therefore, in the following in vitro experiments, we used $\mathrm{EGF}$ and $\mathrm{HaCaT}$ cells to mimic the in vivo conditions of re-epithelization.

As shown in Fig. 4A1, in response to EGF stimuli, upregulated Kindlin-1 expression was detected $3 \mathrm{~h}$ after and sustained until the end of the observation $(24 \mathrm{~h}, 2.47$-fold vs. $0 \mathrm{~h}$, Fig. 4A2). These data confirmed our hypothesis that Kindlin-1 may contribute to EGF-induced re-epithelialization through keratinocytes.

Kindlin-1 shRNA suppresses EGF-induced integrin $\beta 1-F A K$ activation and actin recruitment. It has been documented that there is a highly complex regulation of cell signaling in re-epithelialization (2). To further explore the signal transdution of EGF-Kindlin-1 in HaCaT cells, we employed Kindlin-1 shRNA to search for downstream regulators. The interference and knockdown efficiency was confirmed by fluorescence microscopy (Fig. 4B) and western blot analysis (Fig. 4C). The Kindlin-1 knockdown population (Kindlin-1 shRNA) and the scrambled-RNAi population (Control shRNA) of HaCaT cells were used in the following assays.

Integrin $\beta 1$ is one the best candidates of the downstream regulators either for its potential binding sites of Kindlin-1 or for its critical role in promoting re-epithelialization $(27,28)$. In our study, EGF triggered integrin $\beta 1$ expression and its activation was confirmed in Fig. 5A1-A4. Although Kindlin-1 knockdown yielded no obvious changes in integrin $\beta 1$ protein expression (Fig. 5B1 and B3), reduced integrin $\beta 1$ activation [integrin $\beta 1$ (ac)] was observed in the EGF $0 \mathrm{~h}$ group, approximately $36 \%$ (Fig. 5B2, lane 3 vs. lane 2); a greater reduction was observed in the EGF $24 \mathrm{~h}$ group, an approximately $58 \%$ decrease when compared to the control shRNA group (Fig. 5B2, lane 6 vs. lane 5). Such findings were confirmed by immunofluorescence staining. Enhanced Kindlin-1 and integrin $\beta 1$ (ac) staining was observed in the cells in the control shRNA group in response to EGF stimuli (Fig. 6B1 vs. A1 and B2 vs. A2), particularly at the cell peripheral sites. Intensive violet fluorescence in the inlays (Fig. 6B2 vs. A2) indicated the increased co-localization of Kindlin-1 and integrin $\beta 1$ (ac) in the EGF-treated control shRNA-transfected cells. However in the cells transfected with Kindlin-1 shRNA, integrin $\beta 1$ (ac) staining was less than that of the control shRNA-transfected cells, whether EGF was present in culture or not. These results implied that EGF evoked both the expression and binding 
A1 +EGF $10 \mathrm{ng} / \mathrm{ml}$

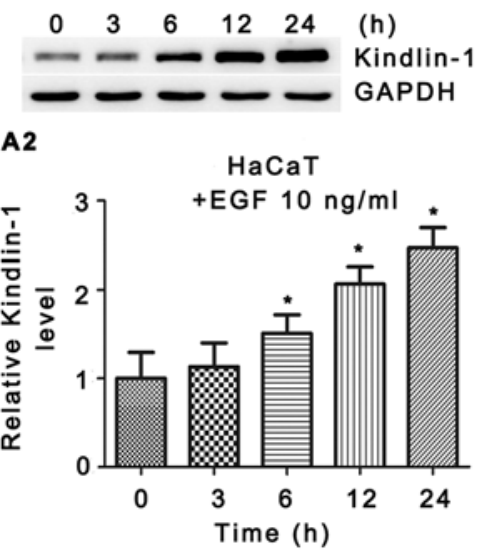

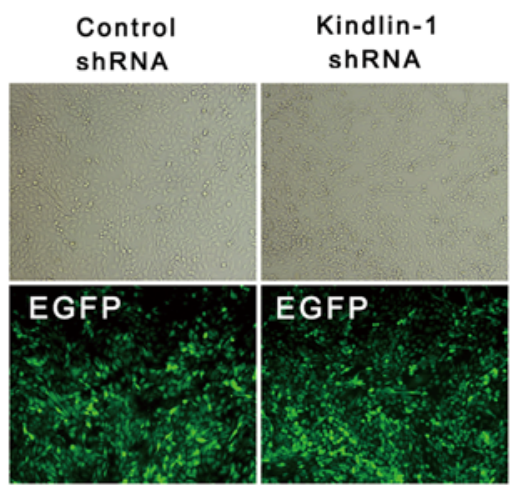

C


Figure 4. Expression of Kindlin-1 in EGF-stimulated HaCaT cells. (A1) Expression of Kindlin-1 in HaCaT cells in response to EGF (10 ng/ml) was assessed by western blot analysis. (A2) Blots were quantified and compared with GAPDH, the graphs show quantification data. Values were reported as the means \pm SEM $(\mathrm{n}=4)$. ${ }^{*} \mathrm{P}<0.05$, significant difference compared to the value at $0 \mathrm{~h}$. (B-C) Knockdown efficiency of Kindlin-1 protein in HaCaT cells was determined by fluorescence microscopy and western blot analysis. Quantification data are shown in the graph $(\mathrm{C}) .{ }^{*} \mathrm{P}<0.05$, significant difference compared with the normal group; ${ }^{\wedge} \mathrm{P}<0.05$, significant difference compared with the control shRNA group. EGF, epidermal growth factor; N, normal HaCaT cells; C, control shRNA-transfected HaCaT cells; K, Kindlin-1 shRNA-transfected HaCaT cells.

A1

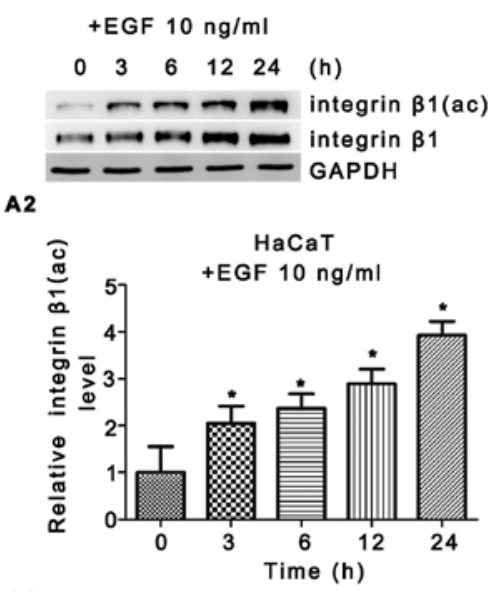

A3

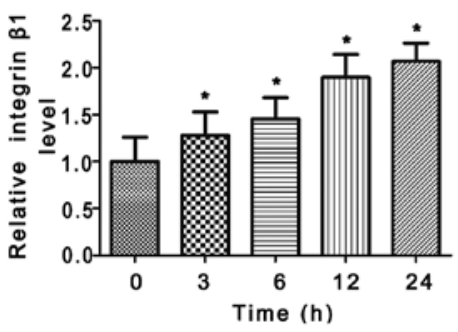

A4

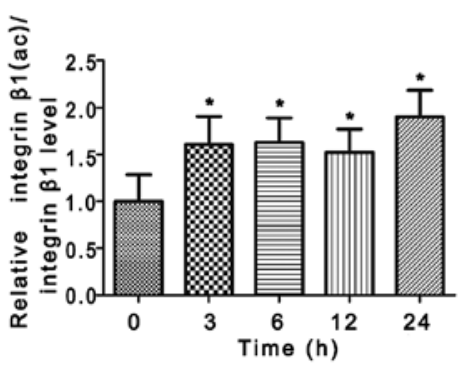

B1
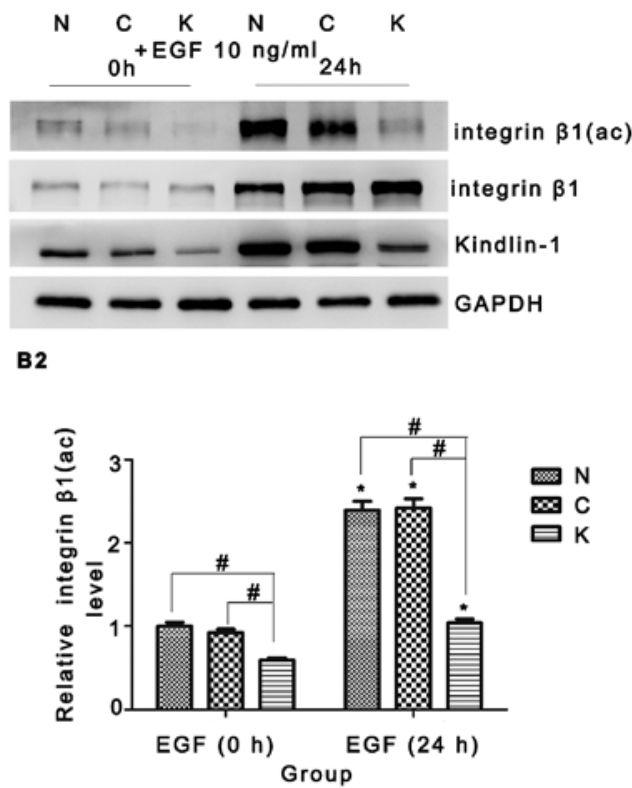

B3

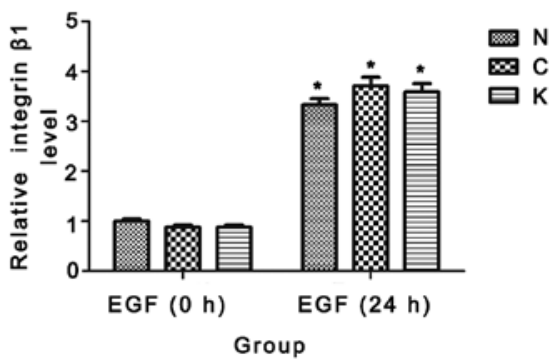

Figure 5. Kindlin-1 knockdown attenuates EGF-induced integrin $\beta 1$ activation. (A1) Normal HaCaT cells were incubated with EGF (10 ng/ml) for the indicated periods of time, integrin $\beta 1$ and its activated form were detected by western blot analysis and quantified in (A2 and A3), integrin $\beta 1$ (ac)/ integrin $\beta 1$ was quantified as shown in (A4). ${ }^{*} \mathrm{P}<0.05$, significant difference compared to the value of the EGF (0 h) group. (B1) Normal, control shRNA- and Kindlin-1 shRNAtransfected $\mathrm{HaCaT}$ cells were incubated with EGF for $24 \mathrm{~h}$, integrin $\beta 1$ and its activated form were detected by western blot analysis and quantified as shown in (B3 and B2). ${ }^{*} \mathrm{P}<0.05$, significant difference compared to the same type of cells in the EGF ( $\left.0 \mathrm{~h}\right)$ group. ${ }^{\#} \mathrm{P}<0.05$. EGF, epidermal growth factor. 


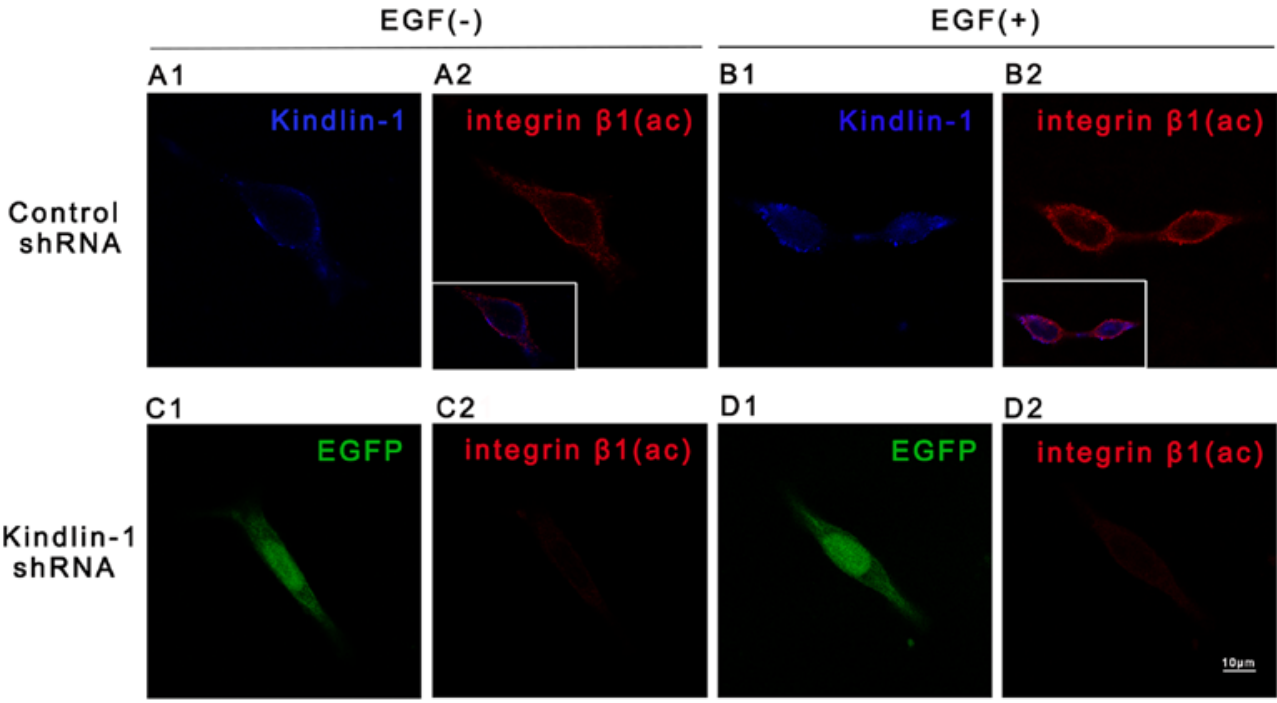

Figure 6. Activated integrin $\beta 1$ staining in HaCaT cells. Cellular localization of activated integrin $\beta 1$ (integrin $\beta 1$ ac) and Kindlin-1 were observed using confocal microscopy. (A1 and A2) Kindlin-1 staining (blue) and integrin $\beta 1$ (ac) (red) in control shRNA-transfected HaCaT cells without EGF stimuli. (B1 and B2) Kindlin-1 (blue) and integrin $\beta 1$ (ac) (red) staining in control shRNA-transfected HaCaT cells exposed for $6 \mathrm{~h}$ to $10 \mathrm{ng} / \mathrm{ml} \mathrm{EGF}$. (C1 and C2) EGFP (green) and integrin) $\beta 1$ ) (ac) staining (red) in Kindlin-1 shRNA-transfected HaCaT cells without EGF stimuli. (D1 and D2) EGFP (green) and integrin) ß1) (ac) staining) (red) in Kindlin-1 shRNA-transfected HaCaT cells with EGF stimuli. Co-localization of integrin $\beta 1$ (ac) and Kindlin-1 is shown in the inlays of panels A2 and B2 (violet). Scale bar, $10 \mu \mathrm{m}$. EGF, epidermal growth factor.
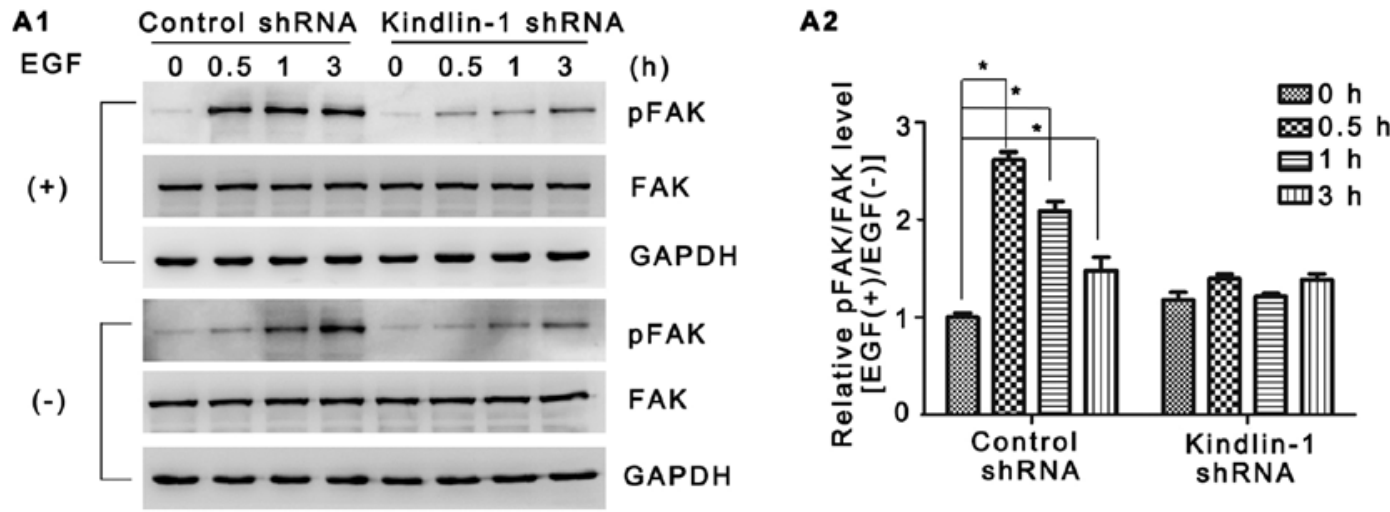

Figure 7. Kindlin-1 knockdown attenuates EGF-stimulated FAK phosphorylation in HaCaT cells. Detached serum-starved control HaCaT cells and Kindlin-1 shRNA-transfected HaCaT cells were stimulated with or without EGF (10 ng/ml) for 15 min and then subjected to FN-coated dishes for 30 min, $1 \mathrm{~h}$ and 3 h, respectively. (A1) phospho-FAK (p-FAK) and FAK levels were detected by western blot analysis and with GAPDH as an internal control. (A2) EGF induced $p-F A K / F A K$ expression was presented by the fold changes compared with the value of control shRNA [EGF(+)/EGF(-), 0 h]. ${ }^{*} \mathrm{P}<0.05$. EGF, epidermal growth factor; FAK, focal adhesion kinase.

of Kindlin-1 and integrin $\beta 1$ (ac), while Kindlin-1 shRNA suppressed this effect. Together with the regulatory role of Kindlin-1 in integrin $\beta 1$ trafficking (29), our data indicated that Kindlin-1 was very likely to be a mediator of EGF-induced integrin $\beta 1$ signaling.

FAK is a widely expressed non-receptor tyrosine kinase which is responsible for multiple cell functions by mediating integrin signaling transduction (30-32). In our study, of note, although no obvious difference was observed in FAK expression between the groups, EGF-induced FAK activation was confirmed in the control shRNA-transfected $\mathrm{HaCaT}$ cells by both western blot analysis and immunofluorescence staining (Figs 7A1 and 8B2 vs. A2). In contrast, both adhesion-dependent FAK autophosphorylation (Figs 7A1 and 8C2 vs. A2,) and EGF-stimulated FAK phosphorylation were partly abolished in the Kindlin-1 knockdown group (Figs 7A1 and 8D2 vs. B2).
Fold changes in FAK phosphorylation following exposure to EGF were quantified as shown in Fig. 7A2. Furthermore, exposure to EGF increased the co-localization of Kindlin-1 and p-FAK in the control HaCaT cells (inlay of Fig. 8B2 vs. A2). Combined with our findings shown in Fig. 6, the abovementioned data proved that the Kindlin-1-integrin $\beta 1$-FAK complex formed at cell peripheral sites and suggested the existence of an EGF-Kindlin-1-integrin $\beta 1$-FAK signaling pathway in $\mathrm{HaCaT}$ cells.

Actin is another candidate of downstream regulators of EGF-Kindlin-1 either for its indirect interaction to Kindlin-1 through migfilin, or its direct binding to the intracellular part of integrin $\beta 1(18,33)$. Through the adjustment of its organization, the actin cytoskeleton contributes to integrinmediated outside-in and inside-out signal transduction. Our results demonstrated that, following culture with EGF, more 


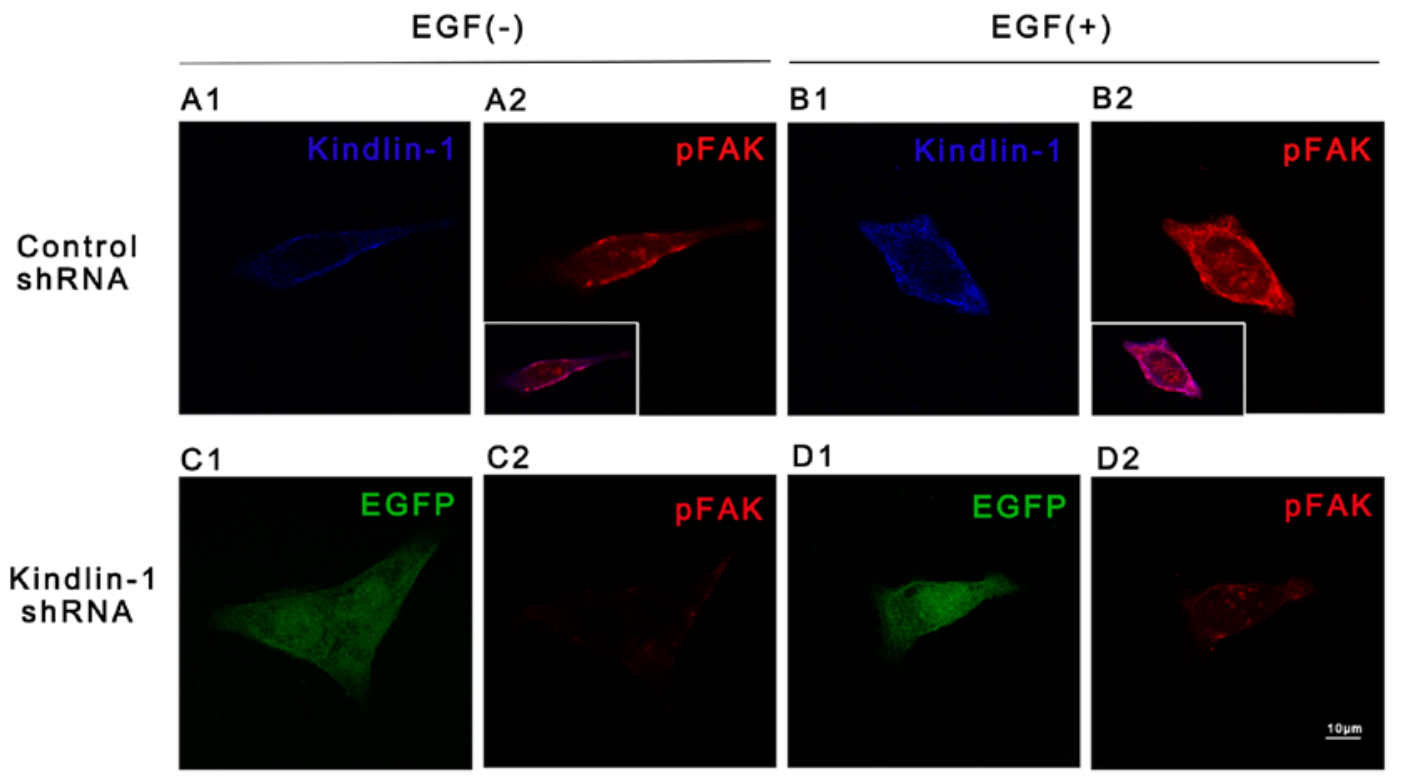

Figure 8. Phospho-FAK staining in HaCaT cells. Cellular localization of p-FAK and Kindlin-1 was observed using confocal microscopy. (A1 and A2) Kindlin-1 staining (blue) and p-FAK (red) in control shRNA-transfected HaCaT cells without EGF stimuli. (B1-B2) Kindlin-1 staining (blue) and p-FAK (red) in control shRNA-transfected $\mathrm{HaCaT}$ cells with $1 \mathrm{~h}$ exposure to $10 \mathrm{ng} / \mathrm{ml} \mathrm{EGF}$. (C1 and C2) EGFP (green) and p-FAK staining (red) in Kindlin-1 shRNA-transfected HaCaT cells without EGF stimuli. (D1 and D2) EGFP (green) and p-FAK staining (red) in Kindlin-1 shRNA-transfected HaCaT cells with EGF stimuli. Co-localization of p-FAK and Kindlin-1 are shown in the inlays of (A2 and B2) (violet). Scale bar, $10 \mu \mathrm{m}$. FAK, focal adhesion kinase; EGF, epidermal growth factor.

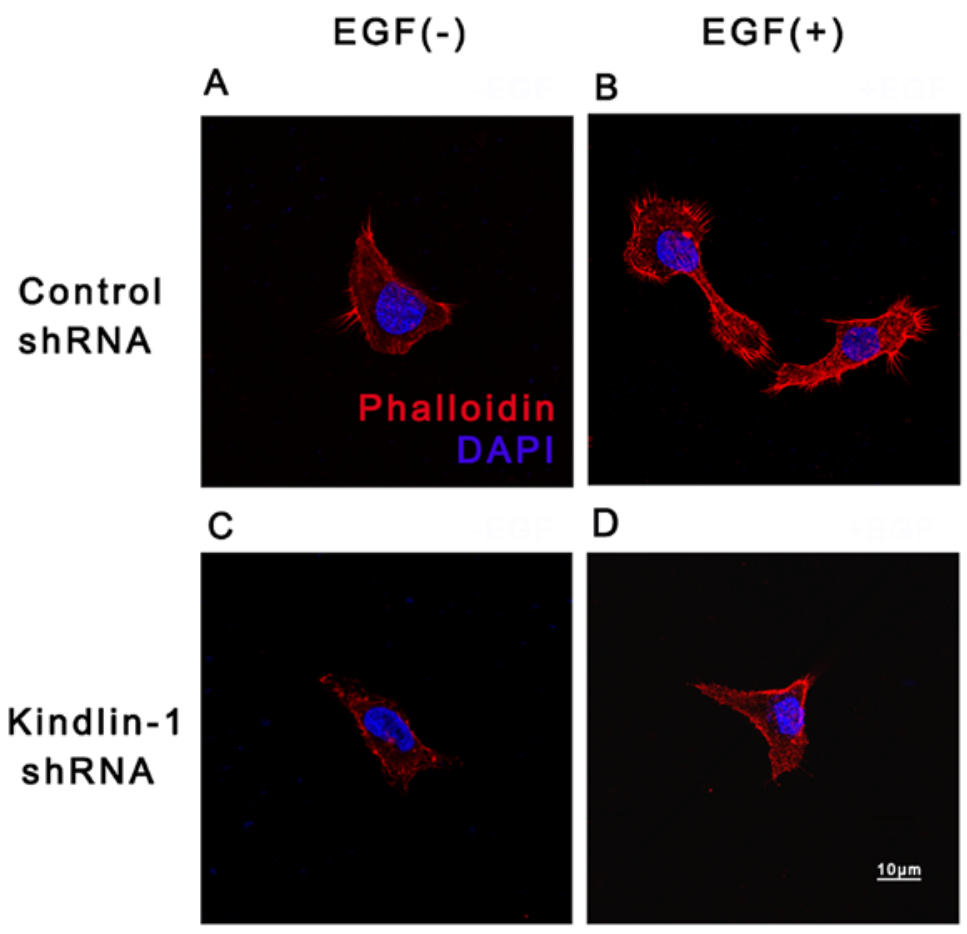

Figure 9. EGF-induced F-actin re-arrangement is disrupted by kindlin-1 shRNA. Staining of F-actin in HaCaT cells was by visualized with phalloidin staining (red) and confocal microscopy, DAPI counterstaining for cell nuclei (blue). (A) Control shRNA-transected HaCaT cells without EGF stimuli. (B) Control shRNAtransected $\mathrm{HaCaT}$ cells cultured with EGF for $6 \mathrm{~h}$. (C) Kindlin-1 shRNA-transfected HaCaT cells without EGF stimuli. (D) Kindlin-1 shRNA-transfected HaCaT cells cultured with EGF for $6 \mathrm{~h}$. Scale bar, $10 \mu \mathrm{m}$.

obvious cell actin was concentrated at cell extensions and/or cell borders (Fig. 9B) when compared with EGF(-) deprived control cultures (Fig. 9A). However, in the Kindlin-1 knockdown group, the actin network was disorganized and disrupted (Fig. 9D vs. C), suggesting that EGF-induced actin reorganization may be partly dependent on Kindlin-1.
Although previous studies have proven that there is no catalytic activity, Kindlin-1 may regulate cell functions by integrating and transmitting cell signals $(16,17,34)$. In this study, in the presence of EGF, the potential role of Kindlin-1 in actin re-organization and its increased binding to integrin $\beta 1$, as well as FAK, strongly suggested that Kindlin-1 may influence cell 

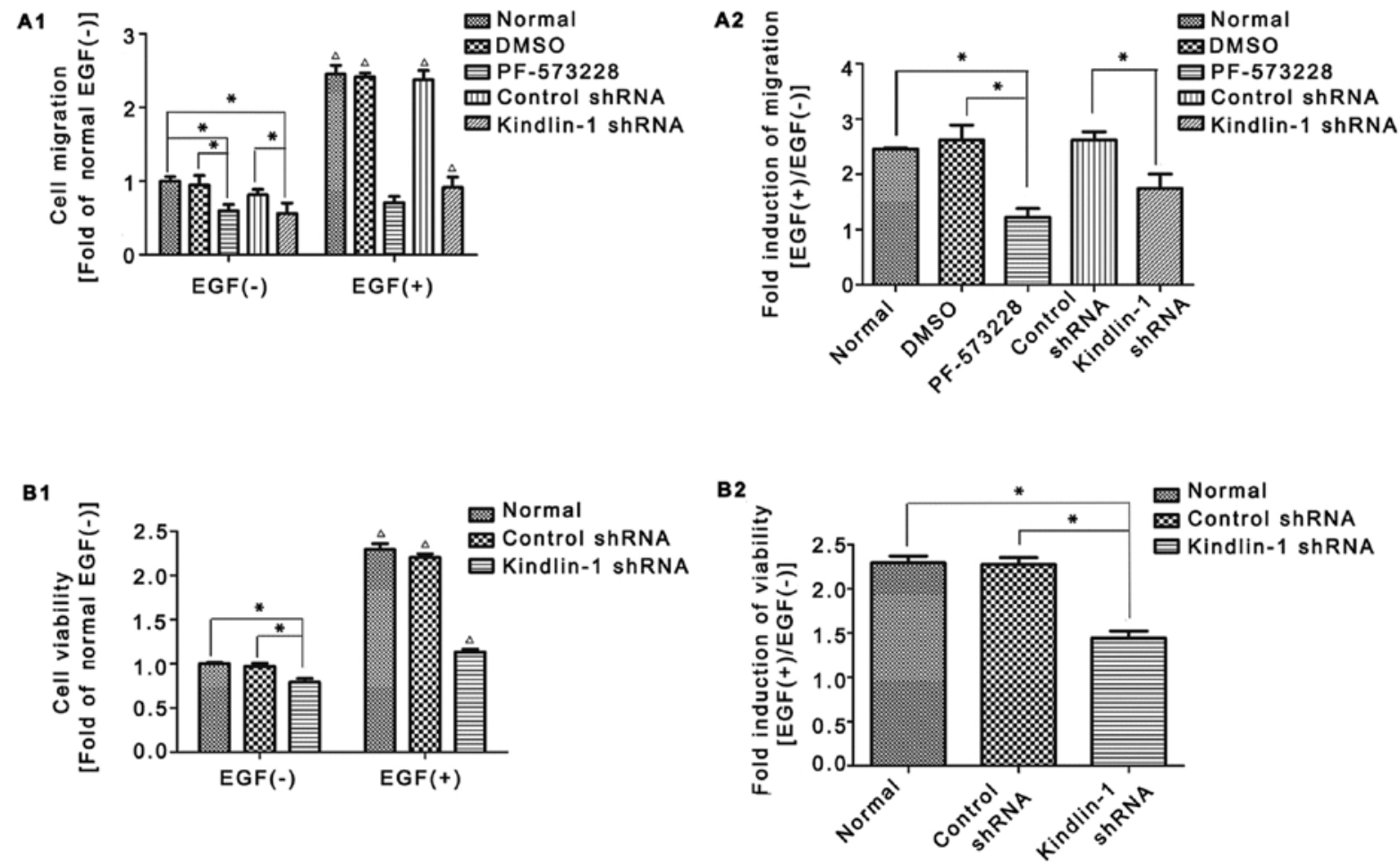

Figure 10. Kindlin-1 shRNA inhibits EGF-induced migration and proliferation of HaCaT cells. Normal, control shRNA- and Kindlin-1 shRNA-transected HaCaT cells were examined by Transwell assay, Normal cells were pre-treated with or without PF573228 ( $1 \mu \mathrm{M}, 30 \mathrm{~min})$ followed by EGF (10 ng/ml, $24 \mathrm{~h})$. (A1) Cell migration was quantified by comparing with Normal [EGF(-)]. (A2) EGF-induced fold changes in cell migration in each group. After being incubated with or without EGF $(10 \mathrm{ng} / \mathrm{ml})$ for $24 \mathrm{~h}$, Normal, control shRNA- and Kindlin-1 shRNA-transfected HaCaT cells were examine by CCK8 assay. (B1) Cell proliferation was quantified by comparing with normal group [EGF(-)]. (B2) EGF-induced fold changes in cell proliferation in each type of cells. "P<0.05 and ${ }^{\wedge} \mathrm{P}<0.05$, significant difference compared with the relative cells in the EGF(-) group. EGF, epidermal growth factor.

behavior in wound healing by directly or indirectly binding to signaling proteins and mediating protein interactions.

Kindlin-1 shRNA suppresses EGF-induced HaCaT cell migration and proliferation. To verify the above hypothesis, we then focused on examining the influence of Kindlin-1 on integrin $\beta 1$ and FAK-related cell functions. During re-epithelization, keratinocytes migrate to the wound center and proliferate to fill the skin defect $(35,36)$. Indeed, Kindlin-1 shRNA-mediated abnormal integrin regulation caused cell behavior defects: Transwell assay revealed that in the absence of EGF, PF-573228 suppressed EGF-induced HaCaT cell migration (Fig.10A1, lane 3 vs. lane 2); likewise, Kindlin-1 shRNA attenuated $\mathrm{HaCaT}$ cell migration compared to the control shRNA group (Fig. 10A1, lane 5 vs. lane 4). More marked differences were observed between the Kindlin-1 shRNA- and control shRNA-transfected cells following stimulation with EGF (Fig. 10A1, lane 10 vs. lane 9). The fold induction of cell migration following exposure to EGF was quantified as shown in Fig. 10A2 [EGF(+)/EGF(-)], Kindlin-1 shRNA restrained cell migration compared to the control shRNA group (approximately $35 \%$ reduction, lane 5 vs. lane 4), indicating Kindlin-1 shRNA partly abolished EGF induced migration.

Similar changes were observed for cell proliferation. Under normal conditions, slightly impaired cell proliferation was observed in the Kindlin-1 shRNA-transfected cells (Fig. 10B1, lane 3 vs. lane 2), while in the presence of EGF, a more rapid difference was observed between the groups (Fig. 10B1, lane 6 vs. lane 5). The fold induction of cell viability following exposure to EGF was quantified as shown in Fig. 10B2 [EGF(+)/ EGF(-)]; Kindlin-1 shRNA repressed cell proliferation compared to the control shRNA group (approximately $45 \%$ reduction, lane 3 vs. lane 2 ).

Taken together, the inhibition of Kindlin-1 expression in $\mathrm{HaCaT}$ cells partially weakened EGF-induced integrin $\beta 1$-FAK activation and the recruitment of cytoskeletal proteins, which finally led to impaired cell functions, including migration and proliferation. These results confirm the role of Kindlin-1 in transmitting EGF activation signals in skin wound healing.

\section{Discussion}

Multiple stimuli are responsible for inducing cell migration and proliferation during re-epithelialization, including an absence signal transmitted from the free edge of the wound and the increasing expression of growth factors (e.g., EGF and TGF). Clinical applications of growth factors in wound healing have been rapidly developed. In China, human recombinant EGF and basic fibroblast growth factor (bFGF) have been commercially available, and the topical administration of these growth factors has been proven to be effective for wound healing in clinical practice. Fully understanding the downstream signaling of EGF will allow for the more precise control of skin wound healing.

It has been reported that the major function of EGF in acute wounds is re-epithelialization (4). Keratinocytes are the main cell components of the epithelium, and also the main executors of re-epithelialization, considering the specific distribution of 
Kindlin-1 in EGF-induced re-epithelialization. In the present study, we proposed a novel hypothesis (to the best of our knowledge) that in skin wound healing, EGF induced kindlin-1, which in turn activated intergrin $\beta 1$ signaling to promote HaCaT keratinocyte activation.

By using full-thickness excisional wound models, the upregulated expression of kindlin-1 was observed in the epidermis. Indeed, the increased expression was not only detected in the EGF-treated group, but also in the untreated controls. This may at least partly be due to endogenic EGF. In the normal healing process, following injury, EGF is synthesized by platelets, lymphocytes, macrophages and fibroblasts, which acts on keratinocytes in a paracrine manner and finally contributes to keratinocyte activation $(7,8)$. By contrast, in our study, the topical application of EGF directly acted on wounds at a higher concentration, thus accelerating the above-mentioned bio-effects. This may explain why the more rapid and durable upregulation of Kindlin-1 was found in the EGF-treated group (Fig. 1).

Considering the expression of Kindlin-1 in the epidermis and its enrichment in response to EGF, we then sought to explore its role in re-epithelialization, particularly in keratinocyte bioactivity. It has been demonstrated that Kindlins are co-activator of integrins (37). Evidence of the role of integrins in cell signal transmitting has accumulated. In the wound epidermis, intergrin $\beta 1$ has been reported to serve as a bidirectional signal transduction molecule by binding to various signaling effectors directly or indirectly (38). These intergrin $\beta 1$-related protein complexes convey signals, regulating gene expression and cell behavior, such as cell proliferation, migration and adhesion, as well as cell survival (39). Based on such observations, we hypothesized that Kindlin-1 may affect cell bioactivity through integrin $\beta 1$. As expected, EGF stimuli evoked integrin $\beta 1$ activation in HaCaT keratinocytes, and the blockade of Kindlin-1 led to decreased integrin $\beta 1$ activation compared to the normal and control group (Fig. 5).

The activation of integrins allows the binding of intracellular signaling molecules, such as FAK, Src, p130C and other structural proteins. Up to 180 different scaffold and signaling proteins have been reported to be included in this network (40). As regards FAK for example, integrin activation can promote the combination of integrin and the ECM ligand and helps to form focal adhesion, which recruits focal adhesion proteins, including FAK. The $\beta$ subunit of integrins can bind to the $\mathrm{N}$-terminal regions of FAK to induce a structural change. FAK then switches to an active state (autophosphorylation of Tyr397) and triggers the downstream signaling pathway (41). FAK activation often occurs as a result of growth factor stimulation $(42,43)$. In this study, we also observed FAK phosphorylation in response to EGF stimuli in serum-starved normal HaCaT cells, (Fig. 7), which is consistent with the study by Kim and Kim (44). However, in the Kindlin-1 shRNA group, the upregulation of FAK was attenuated. One reason may explain this phenomenon: in nomal $\mathrm{HaCaT}$ cells, integrin-mediated cell adhesion through focal adhesion provided the signaling transduction platform to activate FAK, and EGF accelerated this process. However, in Kindlin-1 shRNA-transfected $\mathrm{HaCaT}$ cells, the depletion of Kindlin-1 resulted in the impaired activation of integrin $\beta 1$, thus affecting the subsequent 'platform' foundation and FAK activation.
The activation of integrin-FAK and changes in actin conformation are related to several keratinocyte functions associated with wound healing. In this study, we first evaluated the role of Kindlin-1 in EGF-induced HaCaT cell migration and proliferation, two striking features of keratinocytes during re-epithelialization. Our results revealed that Kindlin-1 inhibition significantly attenuated EGF-induced $\mathrm{HaCaT}$ cell migration (Fig. 10A1 and A2) and proliferation (Fig. 10B1 and B2). These results indicated the existence of an EGF-Kindlin-1-integrin $\beta 1$-FAK axis in triggering $\mathrm{HaCaT}$ cell activation.

It worth determining whether Kindlin-1 alone fulfilled the above function or cooperated with other molecules. In a previous study, Kindlin-2, another member of the Kindlins, was implicated in wound closure and tissue repair by acting on fibroblasts (45). Moreover, functional similarities between Kindlin-1 and Kindlin-2 have been reported, as they are localized in epidermal keratinocytes and have overlapping functions in adhesion and survival (46). Thus, Kindlin-1 and Kindlin-2 may function together in keratinocyte integrin activation during wound healing. However, this hypothesis and the exact mechanisms warrant further investigation.

In conclusion, our data provide evidence that in $\mathrm{HaCaT}$ keratinocytes, Kindlin- 1 acts on integrin $\beta 1$, FAK and actin to trigger cell activation. The inhibition of Kindlin-1 expression in $\mathrm{HaCaT}$ cells significantly attenuates the EGF-induced migration and proliferation. Given the essential role of keratinocyte activation in wound healing, Kindlin-1 may be a promising therapeutic target to promote wound healing.

\section{Acknowledgments}

The present study was supported by the National High-tech R\&D program (863 program, 2014AA020705) and the National Natural Scientific Foundation of China (grant no. 81101178).

\section{References}

1. Greaves NS, Ashcroft KJ, Baguneid M and Bayat A: Current understanding of molecular and cellular mechanisms in fibroplasia and angiogenesis during acute wound healing. J Dermatol Sci 72: 206-217, 2013.

2. Pastar I, Stojadinovic O, Yin NC, Ramirez H, Nusbaum AG, Sawaya A, Patel SB, Khalid L, Isseroff RR and Tomic-Canic M: Epithelialization in Wound Healing: A Comprehensive Review. Adv Wound Care (New Rochelle) 3: 445-464, 2014.

3. Werner S and Grose R: Regulation of wound healing by growth factors and cytokines. Physiol Rev 83: 835-870, 2003.

4. Barrientos S, Stojadinovic O, Golinko MS, Brem H and TomicCanic M: Growth factors and cytokines in wound healing. Wound Repair Regen 16: 585-601, 2008.

5. Gurtner GC, Werner S, Barrandon Y and Longaker MT: Wound repair and regeneration. Nature 453: 314-321, 2008.

6. Shiraha H, Glading A, Gupta K and Wells A: IP-10 inhibits epidermal growth factor-induced motility by decreasing epidermal growth factor receptor-mediated calpain activity. J Cell Biol 146: 243-254, 1999.

7. Schultz G, Rotatori DS and Clark W: EGF and TGF-alpha in wound healing and repair. J Cell Biochem 45: 346-352, 1991.

8. Haase I, Evans R, Pofahl R and Watt FM: Regulation of keratinocyte shape, migration and wound epithelialization by IGF-1- and EGF-dependent signalling pathways. J Cell Sci 116: 3227-3238, 2003

9. Eberwein P, Laird D, Schulz S, Reinhard T, Steinberg T and Tomakidi P: Modulation of focal adhesion constituents and their down-stream events by EGF: On the cross-talk of integrins and growth factor receptors. Biochim Biophys Acta 1853 (10 Pt A): 2183-2198, 2015 
10. Singh P, Chen C, Pal-Ghosh S, Stepp MA, Sheppard D and Van De Water L: Loss of integrin alpha9beta1 results in defects in proliferation, causing poor re-epithelialization during cutaneous wound healing. J Invest Dermatol 129: 217-228, 2009.

11. Kenny FN and Connelly JT: Integrin-mediated adhesion and mechano-sensing in cutaneous wound healing. Cell Tissue Res 360: 571-582, 2015.

12. Grose R, Hutter C, Bloch W, Thorey I, Watt FM, Fässler R, Brakebusch C and Werner S: A crucial role of beta 1 integrins for keratinocyte migration in vitro and during cutaneous wound repair. Development 129: 2303-2315, 2002.

13. Chen L, Hughes RA, Baines AJ, Conboy J, Mohandas N and An X: Protein 4.1R regulates cell adhesion, spreading, migration and motility of mouse keratinocytes by modulating surface expression of beta1 integrin. J Cell Sci 124: 2478-2487, 2011

14. Calderwood DA, Campbell ID and Critchley DR: Talins and kindlins: Partners in integrin-mediated adhesion. Nat Rev Mol Cell Biol 14: 503-517, 2013.

15. Kahner BN, Kato H, Banno A, Ginsberg MH, Shattil SJ and Ye F: Kindlins, integrin activation and the regulation of talin recruitment to $\alpha \operatorname{IIb} \beta 3$. PLoS One 7: e34056, 2012.

16. Montanez E, Ussar S, Schifferer M, Bösl M, Zent R, Moser M and Fässler R: Kindlin-2 controls bidirectional signaling of integrins. Genes Dev 22: 1325-1330, 2008.

17. Tu Y, Wu S, Shi X, Chen K and Wu C: Migfilin and Mig-2 link focal adhesions to filamin and the actin cytoskeleton and function in cell shape modulation. Cell 113: 37-47, 2003.

18. Larjava H, Plow EF and Wu C: Kindlins: Essential regulators of integrin signalling and cell-matrix adhesion. EMBO Rep 9: 1203-1208, 2008.

19. Meves A, Stremmel C, Gottschalk K and Fässler R: The Kindlin protein family: New members to the club of focal adhesion proteins. Trends Cell Biol 19: 504-513,2009.

20. Harburger DS, Bouaouina M and Calderwood DA: Kindlin-1 and -2 directly bind the $\mathrm{C}$-terminal region of beta integrin cytoplasmic tails and exert integrin-specific activation effects. J Biol Chem 284: 11485-11497, 2009.

21. Siegel DH, Ashton GH, Penagos HG, Lee JV, Feiler HS, Wilhelmsen KC, South AP, Smith FJ, Prescott AR, Wessagowit V, et al: Loss of kindlin-1, a human homolog of the Caenorhabditis elegans actin-extracellular-matrix linker protein UNC-112, causes Kindler syndrome. Am J Hum Genet 73 174-187, 2003.

22. Ussar S, Wang HV, Linder S, Fässler R and Moser M: The Kindlins: Subcellular localization and expression during murine development. Exp Cell Res 312: 3142-3151, 2006.

23. Ashton GH, McLean WH, South AP, Oyama N, Smith FJ, Al-Suwaid R, Al-Ismaily A, Atherton DJ, Harwood CA, Leigh IM, et al: Recurrent mutations in kindlin-1, a novel keratinocyte focal contact protein, in the autosomal recessive skin fragility and photosensitivity disorder, Kindler syndrome. J Invest Dermatol 122: 78-83, 2004.

24. Herz C, Aumailley M, Schulte C, Schlötzer-Schrehardt U, Bruckner-Tuderman L and Has C: Kindlin-1 is a phosphoprotein involved in regulation of polarity, proliferation, and motility of epidermal keratinocytes. J Biol Chem 281: 36082-36090, 2006.

25. Zhang D, Sun L, Zhu H, Wang L, Wu W, Xie J and Gu J: Microglial LOX-1 reacts with extracellular HSP60 to bridge neuroinflammation and neurotoxicity. Neurochem Int 61: 1021-1035, 2012.

26. Jia D, Duan F, Peng P, Sun L, Ruan Y and Gu J: Pyrroloquinolinequinone suppresses liver fibrogenesis in mice. PLoS One 10 e0121939, 2015.

27. Li JF, Duan HF, Wu CT, Zhang DJ, Deng Y, Yin HL, et al: HGF accelerates wound healing by promoting the dedifferentiation of epidermal cells through $\beta 1$-integrin/ILK pathway. BioMed Res Int 470418: 2013, 2013.
28. Iwata Y, Akamatsu H, Hasegawa S, Takahashi M, Yagami A Nakata S and Matsunaga K: The epidermal Integrin beta-1 and p75NTR positive cells proliferating and migrating during wound healing produce various growth factors, while the expression of p75NTR is decreased in patients with chronic skin ulcers. J Dermatol Sci 71: 122-129, 2013.

29. Margadant C, Kreft M, Zambruno G and Sonnenberg A: Kindlin-1 regulates integrin dynamics and adhesion turnover. PLoS One 8: e65341, 2013.

30. Parsons JT: Focal adhesion kinase: The first ten years. J Cell Sci 116: 1409-1416, 2003.

31. Mitra SK, Hanson DA and Schlaepfer DD: Focal adhesion kinase: In command and control of cell motility. Nat Rev Mol Cell Biol 6: 56-68, 2005.

32. McLean GW, Carragher NO, Avizienyte E, Evans J, Brunton VG and Frame MC: The role of focal-adhesion kinase in cancer - a new therapeutic opportunity. Nat Rev Cancer 5: 505-515, 2005.

33. Geiger B, Spatz JP and Bershadsky AD: Environmental sensing through focal adhesions. Nat Rev Mol Cell Biol 10: 21-33, 2009.

34. Shi X, Ma YQ, Tu Y, Chen K, Wu S, Fukuda K, Qin J, Plow EF and Wu C: The MIG-2/integrin interaction strengthens cellmatrix adhesion and modulates cell motility. J Biol Chem 282: 20455-20466, 2007.

35. Frank DE and Carter WG: Laminin 5 deposition regulates keratinocyte polarization and persistent migration. J Cell Sci 117: 1351-1363, 2004.

36. Danussi C, Petrucco A, Wassermann B, Pivetta E, Modica TM, Del Bel Belluz L, Colombatti A and Spessotto P: EMILIN1- $\alpha 4 /$ $\alpha 9$ integrin interaction inhibits dermal fibroblast and keratinocyte proliferation. J Cell Biol 195: 131-145, 2011.

37. Böttcher RT, Lange A and Fässler R: How ILK and kindlins cooperate to orchestrate integrin signaling. Curr Opin Cell Biol 21: 670-675, 2009.

38. Longmate WM and Dipersio CM: Integrin Regulation of Epidermal Functions in Wounds. Adv Wound Care (New Rochelle) 3: 229-246, 2014

39. Koivisto L, Heino J, Häkkinen L and Larjava H: Integrins in Wound Healing. Adv Wound Care (New Rochelle) 3: 762-783, 2014.

40. Zaidel-Bar R and Geiger B: The switchable integrin adhesome. J Cell Sci 123: 1385-1388, 2010.

41. Cooper LA, Shen TL and Guan JL: Regulation of focal adhesion kinase by its amino-terminal domain through an autoinhibitory interaction. Mol Cell Biol 23: 8030-8041, 2003.

42. Golubovskaya V, Beviglia L, Xu LH, Earp HS III, Craven R and Cance W: Dual inhibition of focal adhesion kinase and epidermal growth factor receptor pathways cooperatively induces death receptor-mediated apoptosis in human breast cancer cells. J Biol Chem 277: 38978-38987, 2002.

43. Sieg DJ, Hauck CR, Ilic D, Klingbeil CK, Schaefer E, Damsky CH and Schlaepfer DD: FAK integrates growth-factor and integrin signals to promote cell migration. Nat Cell Biol 2: 249-256, 2000.

44. Kim SH and Kim SH: Antagonistic effect of EGF on FAK phosphorylation/dephosphorylation in a cell. Cell Biochem Funct 26: 539-547, 2008

45. He Y, Esser P, Schacht V, Bruckner-Tuderman L and Has C: Role of kindlin-2 in fibroblast functions: Implications for wound healing. J Invest Dermatol 131: 245-256, 2011.

46. He Y, Esser P, Heinemann A, Bruckner-Tuderman L and Has C: Kindlin-1 and -2 have overlapping functions in epithelial cells implications for phenotype modification. Am J Pathol 178: 975-982, 2011. 